\title{
Pathology of the heart and the cardiac conduction system in Wegener's granulomatosis
}

\author{
D C ALLEN, ^ C C DOHERTY,† D P J O'REILLY† \\ From the ${ }^{\star}$ Histopathology Laboratory and $†$ Department of Nephrology, Belfast City Hospital, Belfast, Northern \\ Ireland
}

SUMMARY Two cases of Wegener's granulomatosis occurred in two women aged 53 and 67 years. The clinical course in both was of rapid deterioration resulting from renal failure and leading to death. At necropsy both cases showed severe and disseminated necrotising granulomatosis in the lungs, kidneys, and spleen but with variable degrees of cardiac and systemic vasculitis. One patient, with appreciable cardiac damage, developed a $\mathbf{P}$ wave abnormality due to atrial disease.

In patients with Wegener's granulomatosis damage to the heart should be suspected and signs of conduction system abnormalities looked for on the electrocardiogram.

Since the initial description by Klinger in $1931^{1}$ and confirmation by Wegener in 1936, ${ }^{2}$ Wegener's granulomatosis has emerged as an uncommon disease entity of unknown aetiology. The disease is characterised by a necrotising granulomatous vasculitis which most commonly affects the upper and lower respiratory tract and kidneys. Systemic vasculitis and splenic involvement are present to a variable extent. ${ }^{34} \mathrm{~A}$ localised form limited to the respiratory tract has been reported. 5 The emphasis on involvement of the respiratory tract and kidney may be inappropriate as the potentially diffuse nature of the disease, particularly that affecting the heart, may be overlooked. We report two cases of Wegener's granulomatosis with reference to cardiac involvement.

\section{Patients and methods}

\section{PATHOLOGICAL EXAMINATION}

Both cases underwent full postmortem examination. After conventional examination of the hearts detailed attention was paid to the sinus and atrioventricular nodes, the bundle of His, and proximal bundle branches. Serial blocks of these regions were taken, and two out of every 20 consecutive paraffin embedded sections were stained with haematoxylin and eosin and elastic van Gieson stains. Sections were cut

Requests for reprints to Dr Derek C Allen, Histopathology Laboratory, The Laboratories, Belfast City Hospital, Belfast BT9 7AB, Northern Ireland.

Accepted for publication 7 August 1984 at $6 \mu \mathrm{m}$ intervals. Further serial blocks adjacent to the nodal structures and their approaches identified the arteries supplying the nodes.

\section{CASE 1}

A 53 year old woman was admitted for investigation of advanced uraemia. Sixteen months previously she had been treated in hospital for an acute exacerbation of chronic bronchiectasis, and a high blood urea concentration was noted $(30.0 \mathrm{mmol} / \mathrm{l})$. The blood urea subsequently fell to normal, but microhaematuria with a pronounced increase in erythrocyte sedimentation rate (70-130 $\mathrm{mm}$ in first hour) persisted, and she developed peripheral neuropathy and polyarthralgia. Eight months before admission renal function tests had shown mild impairment; the blood urea concentration was $13 \mathrm{mmol} / \mathrm{l}$, and the creatinine clearance 145 $\mu \mathrm{mol} / \mathrm{l}$.

On admission she was mentally confused and had skin purpura and uveitis. Severe renal failure was present with a blood urea concentration of 45.3 $\mathrm{mmol} / \mathrm{l}(2.7 \mathrm{mg} / 100 \mathrm{ml})$, a serum potassium concentration of $4.0 \mathrm{mmol}(\mathrm{mEq}) / 1$, a serum creatinine concentration of $579 \mu \mathrm{mol} / \mathrm{l}(6.5 \mathrm{mg} / 100 \mathrm{ml})$, a creatinine clearance of $4 \mathrm{ml} / \mathrm{minute}$, and a urine protein concentration of $0.7 \mathrm{~g} / 24$ hours. Peripheral blood eosinophilia was noted (total white cell count $11 \times 10^{9} / 1,4 \%$ eosinophils). The serum calcium concentration was $2.27 \mathrm{mmol} / 1(9.1 \mathrm{mg} / 100 \mathrm{ml})$. An electrocardiogram showed sinus rhythm with a PR interval of $200 \mathrm{~ms}$ and a biphasic $P$ wave in lead V1 which was not present on a recording six weeks earlier. Gangrene of both 
lower limbs developed, and her condition deteriorated rapidly despite treatment with anticoagulation and peritoneal dialysis. She died after nine days in hospital.

\section{Necropsy findings}

The findings at necropsy were of a severe and disseminated necrotising granulomatosis affecting the lungs, kidneys, spleen, skin, and heart. A florid systemic vasculitic component was present in these organs, the aorta, and its main distributing branches. The heavy congested lungs (700 g each) were pneumonic and showed multiple debris-filled cavities in both lower lobes, which measured approximately 3 $\mathrm{cm}$ in diameter. These parenchymal cavities contained creamy necrotic and acute inflammatory slough, walled off by a dense palisading fibrovascular reaction with giant cell forms (negative for tubercle and fungi on both culture and histological staining). The pulmonary arterioles both adjacent to and away from these lesions showed a florid transmural and fibrinoid vasculitis with a heavy infiltrate of polymorphonuclear leucocytes and vessel wall necrosis. Occasional giant cells were seen in these damaged vessels, and special staining showed degenerate clumped elastic tissue. The kidney cortices were pale, and microscopy showed an extensive necrotising glomerulitis with fibrin aggregates and exudates of polymorphonuclear leucocytes. This heavy inflammation centred on glomeruli and radiated out into the surrounding interstitium. Capsular epithelial crescents were present. All sizes of intrarenal vessels were acutely inflamed and fibrinoid in appearance, and there was papillary necrosis. The splenic vessels were affected, and this had resulted in multiple recent infarcts in the enlarged spleen $(320 \mathrm{~g})$.
The purpura noted on clinical examination was due to an acute vasculitic process in the dermis and subcutaneous fat. Other organ damage included capsular vasculitis in the thyroid and pituitary glands. The heart weighed $380 \mathrm{~g}$, the atrial and ventricular components being of a normal size and thickness. Coronary artery atheroma was minimal. There was a fibrinous pericarditis, and the endocardial aspects of both atria (especially the left) were thickened by raised, yellow, and circumscribed plaques measuring $2.0 \mathrm{~cm}$ in diameter. Microscopy showed thickened and inflamed atrial endocardia with foci of fibrinoid necrosis and a palisading granulomatous reaction of inflammatory cells. (Fig. 1). Similar foci were present in the epicardium, the base of the mitral valve, and the myocardium of the proximal interventricular septum, where giant cells were present. Throughout the rest of the myocardium there were diffuse foci of fibrosis and scattered aggregates of eosinophils. Intramyocardial vessels were inflamed and fibrinoid in appearance. The intima of the aorta and iliac arteries was affected by this granulomatous vasculitis, and the left posterior tibial artery and vein were occluded secondary to vasculitic thrombosis.

The coronary arteries were widely patent. The intima was focally inflamed, but there was no overlying thrombosis. The artery supplying the sinus node was patent and was not affected. The sinus node showed loss of conducting myofibres and excess fibrous tissue but no recent or active damage. Orientated to the sinus node there was a fibrinous pericarditis and foci of endocarditis with thrombus formation in the antrum atrii dextri. The pericarditis had also surrounded but not directly involved epicardial ganglia and nerve trunks. The central artery to the atrioventricular node was only mildly inflamed in con-

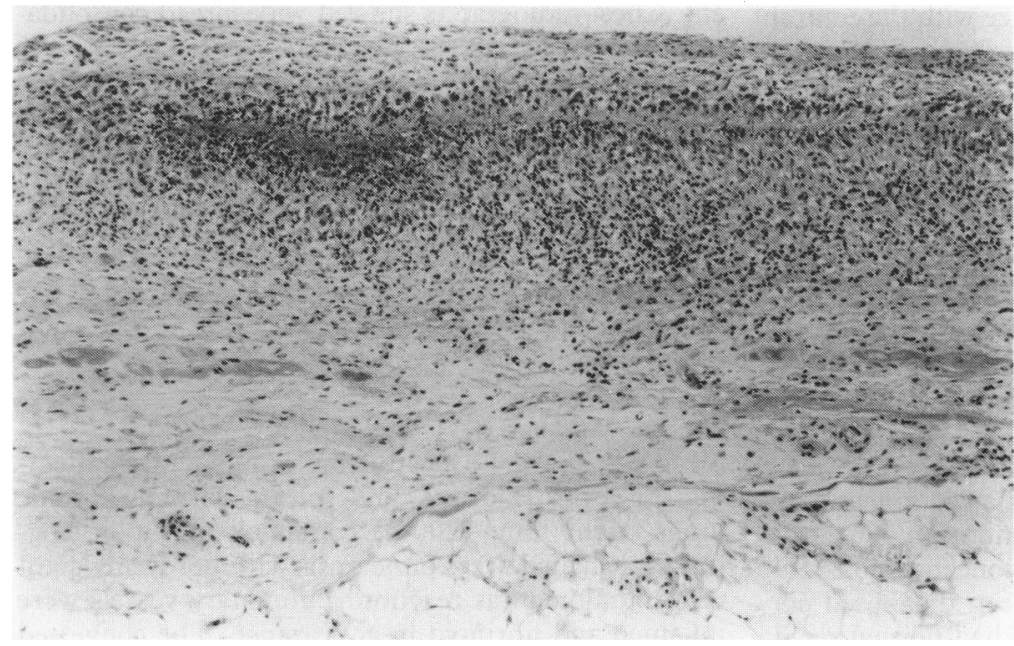

Fig. 1 Histological section showing the thickened and inflamed left atrial endocardium with foci of fibrinoid necrosis and a palisading granulomatous inflammatory reaction. Haematoxylin and eosin, original magnification $\times 125$. 


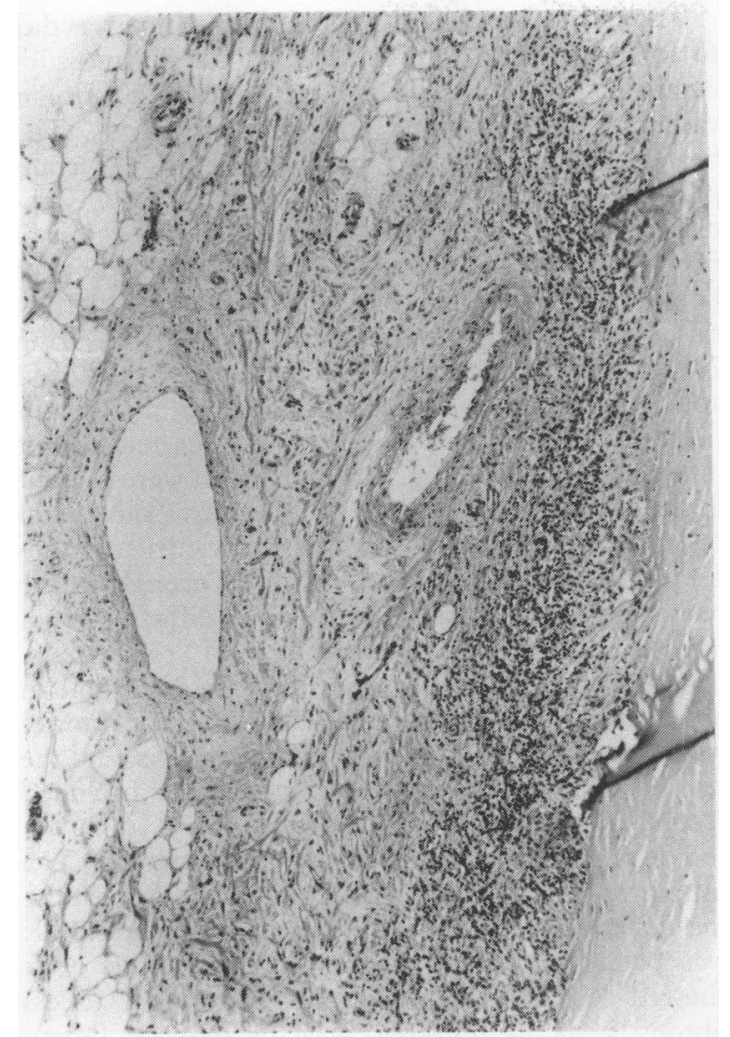

Fig. 2 Histological section showing the atrioventricular node with its central artery. Right atrial subendocardial fat is present on the left. Note the slender branching nodal myofibres and diffuse inflammation, particularly heary at the interface with the central fibrous body (on the right). Haematoxylin and eosin, original magnification $\times 125$.

trast to severe inflammation in the atrioventricular node itself, particularly at its interface with the central fibrous body (Fig. 2), and in the overlying right atrial endocardium.

The penetrating portion of the His bundle contained foci of inflammatory cells, fibrinoid granulomata, and inflamed vascular branches with necrosis of myofibres (Fig. 3). The central fibrous body showed patchy inflammatory infiltrates. The right bundle branch was normal, but focal left ventricular endocarditis was identified in relation to divisions of the left bundle branches at upper and mid septal levels.

\section{CASE 2}

A 67 year old woman was admitted as an emergency with anaemia (haemoglobin concentration $9.6 \mathrm{~g} / \mathrm{dl}$ ) and advanced uraemia (serum urea concentration 35.4 $\mathrm{mmol} / \mathrm{l}$ ). Mild hypertension had been diagnosed six years previously, at which time she had normal renal

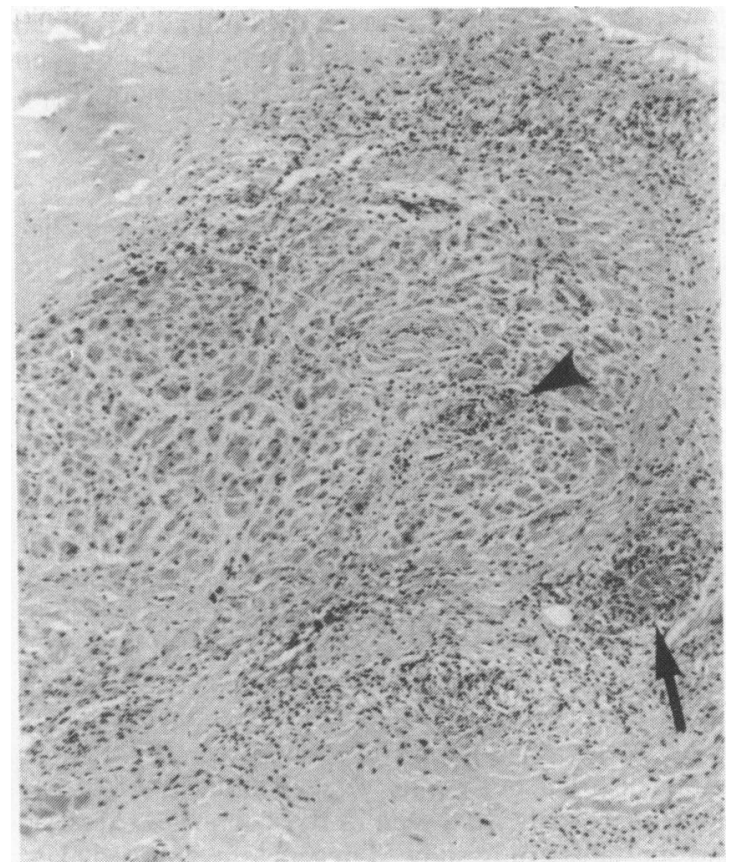

Fig. 3 Histological section showing the His bundle penetrating the centralfibrous body. There are diffuse inflammatory foci and fibrinoid granulomata (arrow). A small central vessel is inflamed and the attendant conducting myofibrils necrotic (arrowhead). Haematoxylin and eosin, original magnification $\times 100$.

function and a normal intravenous pyelogram. Her hypertension was treated with propranolol and spironolactone. On admission she was semiconscious and had nail bed splinter haemorrhages. Her blood pressure was $130 / 80 \mathrm{~mm} \mathrm{Hg}$. A soft ejection systolic murmur and basal inspiratory crepitations were present. Chest radiographs showed widespread consolidation. The total white cell count was $6.4 \times 10^{9} / 1(2 \%$ eosinophils), serum potassium concentration 4.36 $\mathrm{mmol}(\mathrm{mEq}) / \mathrm{l}$, serum creatinine concentration 719 $\mu \mathrm{mol} / 1(7.9 \mathrm{mg} / 100 \mathrm{ml})$, and serum calcium concentration $2.04 \mathrm{mmol} / \mathrm{l}(8.2 \mathrm{mg} / 100 \mathrm{ml})$. Electrocardiographic recordings showed a left ventricular strain pattern and left anterior fascicular block. Antibiotic treatment and peritoneal dialysis were started, but her condition continued to deteriorate, and she died eight days later.

\section{Necropsy findings}

Necropsy showed a necrotising granlomatosis affecting the lungs, kidneys, and spleen. The pneumonic lungs (right lung $1200 \mathrm{~g}$ ) contained multiple geographical shaped areas of necrosis with bordering giant cell granulomatous reaction. Pulmonary vessels were inflamed and fibrinoid in appearance. The congested 
kidneys showed a necrotising glomerulitis with capsular crescent formation, focal vasculitis, and papillary necrosis. The heart weighed $520 \mathrm{~g}$, the coronary arteries were atheromatous, and the myocardium contained foci of ischaemic fibrosis. None of the layers of the heart showed any evidence of active inflammation or vasculitis, and the aorta with its main distributing branches was normal. The vessels supplying the nodes were normal. The sinus node showed loss of myofibres, and the atrioventricular node was normal. The penetrating portion of the His bundle contained an excess of fat cells but viable myofibres and no active inflammation. The bundle branches were not satisfactorily demonstrated.

\section{Discussion}

These two cases illustrate the variable extent to which a coexistent and disseminated systemic vasculitis may be present in Wegener's granulomatosis. This variable vasculitic component has been well documented previously. ${ }^{34}$

As early as 1936 Wegener noted the potential involvement of the heart. ${ }^{2}$ It is tempting to think simplistically of the heart as a folded four chambered vessel prone to the vasculitic lesions seen in other organs, as the patient in case 1 falls at the florid vasculitic end of the Wegener's spectrum with involvement of all the heart layers, the aorta, and its main branches. Thrombosis superimposed on vasculitis of the left posterior tibial artery led to gangrenous changes in the foot. These large vessel changes were seen in combination with visceral arteriolar and venous inflammation resulting in the classical midline organ necroses. In the patient in case 2 the calibre of the vessel affected was arteriolar, and the vasculitis was limited to the lungs, kidneys, and spleen. The heart, aorta, and the main vessels were not affected. Despite this disparity in cardiovascular pathology both patients had a rapidly downhill clinical course, due largely to rapidly progressive renal failure resulting from renal vasculitis.

By 1958, Walton documented a series of 10 patients with Wegener's granulomatosis and reviewed published reports at that time stating that some $11 \%$ had cardiac involvement with granulomata and approximately $28 \%$ focal necrotising arteriolitis of the heart. ${ }^{4}$ A more recent case report and comprehensive review of published reports emphasises the variation in electrocardiographic and morphological findings. ${ }^{6}$ The authors noted coronary arteritis and pericarditis in $50 \%$ of the reported cases of Wegener's granulomatosis, myocarditis in $25 \%$, and myocardial infarction in $11 \%$. Our findings in the patient in case 1 were of a serofibrinous pericarditis, myocarditis, and endocarditis with granulomata; in addition, both extramural and intramural coronary arteritis with foci of myocardial necrosis were present. The heart of the patient in case 2 was not affected. Reported electrocardiographic abnormalities, which were present in under half the cases, were predominantly atrial in origin with atrial tachycardia, flutter, and fibrillation noted by James and Birk. ${ }^{7}$ Of our two patients, one (case 1) developed a bifid P wave in lead V1, and intra-atrial disease in the form of endocarditis was suspected. This was confirmed by necropsy of the atria, which showed raised inflammatory and necrotising plaques similar to those described by Levine and Madden. ${ }^{8}$ Encroachment on to the base of the mitral valve contrasts with the isolated mitral valvulitis documented previously. ${ }^{9}$ Other electrocardiographic findings have indicated pericardial disease, ${ }^{8}$ ventricular fibrillation with myocardial infarction secondary to coronary arteritis, ${ }^{10}$ and "intractable arrhythmias" due to coronary vasculitis. ${ }^{3}$

The sinus and atrioventricular -nodes in man are essentally periarterial structures, and not surprisingly abnormalities of the conduction system may be found in systemic vasculitis. Such changes have been documented for systemic lupus, ${ }^{11}$ rheumatoid arthritis and ankylosing spondylitis, 1213 polyarteritis nodosa, ${ }^{714}$ and scleroderma. ${ }^{15}$ The detection of such lesions is related to the enthusiasm with which they are sought. A description of the anatomy of the cardiac conduction system, its dissection, and treatment of the tissue blocks is readily available in the standard texts. ${ }^{16} 17$ To our knowledge the histological findings in the cardiac conduction system have been described previously in only four instances of Wegener's granulomatosis. ${ }^{718}$

Longauer et al reported the case of a 47 year old woman who developed complete heart block due to granulomatous lesions with hyalinisation and necrosis of the conduction system. ${ }^{18}$ James and Birk reported three cases and emphasised the severity of sinus node involvement and correlated this with the onset of atrial arrhythmias. ${ }^{7}$ They noted sinus node infarcts, necrosis, and granulomata with arteritis, the inflammation being somewhat more pronounced than that in the atrioventricular node. Our patients both showed ageing changes in the sinus node with loss of myofibres but no active inflammation; however, in one (case 1) the pericardium, the tissue surrounding the epicardial ganglia, and the endocardium orientated to the node were inflamed. The functional importance of this is uncertain, since the bifid $P$ wave related to atrial disease and the patient was in sinus rhythm. The atrioventricular node and His bundle were normal in the patient in case 2 , whereas that in case 1 showed granulomata, active inflammation, and focal vasculitis with necrosis. These lesions were similar to those described by Longauer et al in the 
atrioventricular components of the conduction system, ${ }^{18}$ and James and Birk in the sinus nodes of their patients. ${ }^{7}$ Despite these findings in one of our patients (case 1) a conduction abnormality was not apparent on the electrocardiogram (sinus rhythm, PR interval 200 $\mathrm{ms})$. Interestingly, there have been only two reports of complete heart block in Wegener's granulomatosis, ${ }^{6} 18$ and in one the block reversed to right bundle branch block after successful treatment of the clinical exacerbation with temporary pacing and cyclophosphamide. ${ }^{6}$ It should be stressed, however, that since the patient recovered no histological proof was present, and hence involvement of the conduction system by Wegener's granulomatosis could only be assumed. The variability in the extent of the vascular and conduction system involvement is not only confined to Wegener's granulomatosis. Thiene et al in two of three cases of polyarteritis nodosa reported florid sinus node disease but normal atrioventricular nodal and His bundle components. ${ }^{14}$ This disproportionate inflammation of the sinus node has been alluded to by James and Birk who included their three cases of Wegener's granulomatosis as variants of polyarteritis nodosa. ${ }^{7}$

We thank Dr M G McGeown for her kind permission to publish the clinical details of case 2 and $\operatorname{Dr} \mathrm{D} \mathrm{F}$ Hughes, who performed the necropsy.

\section{References}

1 Klinger H. Grenzformen der Periarteritis nodosa. Frankfurter Zeit Path 1931; 42: 455-80.

2 Wegener F. Uber generalisierte, septische Gefasserkrankungen. Verh Dtsch Ges Pathol 1936; 29: 202-10.

3 Fauci AS, Wolff SM. Wegener's granulomatosis: studies in eighteen patients and a review of the literature. Medicine (Baltimore) 1973; 52: 535-61.

4 Walton EW. Giant cell granuloma of the respiratory tract
(Wegener's granulomatosis). $\mathrm{Br} \mathrm{Med} \mathcal{F}$ 1958; ii: 265-70.

5 Carrington CB, Liebow AA. Limited forms of angiitis and granulomatosis of Wegener's type. Am $\mathcal{F}$ Med 1966; 41: 497-527.

6 Forstot JZ, Overlie PA, Neufeld GK, Harmon CE, Forstot SL. Cardiac complications of Wegener's granulomatosis: a case report of complete heart block and review of the literature. Semin Arthritis Rheum 1980; 10: $148-54$.

7 James TN, Birk RE. Pathology of the cardiac conduction system in polyarteritis nodosa. Arch Intern Med 1966; 117: 561-7.

8 Levine H, Madden TJ. Wegener's granulomatosis: report of a case. Am Heart $\mathcal{f}$ 1957; 53: 632-7.

9 Godman GC, Churg J. Wegener's granulomatosis: pathology and review of the literature. Arch Pathol Lab Med 1954; 58: 533-53.

10 Gatenby PA, Lytton DG, Bulteau VG, O'Reilly B, Basten A. Myocardial infarction in Wegener's granulomatosis. Aust NZ F Med 1976; 6: 336-40.

11 James TN, Rupe CE, Monto RW. Pathology of the cardiac conduction system in systemic lupus erythematosus. Ann Intern Med 1965; 63: 402-10.

12 Harris $M$. Rhematoid heart disease with complete heart block. F Clin Pathol 1970; 23: 623-6.

13 James TN. De Subitaneis Mortibus XXIII. Rheumatoid arthritis and ankylosing spondylitis. Circulation 1977; 55: 669-77.

14 Thiene G, Valente M, Rossi L. Involvement of the cardiac conducting system in panarteritis nodosa. Am Heart f 1978; 95: 716-24.

15 Lev M, Landowne M, Matchar JC, Wagner JA. Systemic scleroderma with complete heart block: report of a case with a comprehensive study of the conduction system. Am Heart f 1966; 72: 13-24.

16 Davies MJ, Anderson RH, Becker AE. The conduction system of the heart. London: Butterworths, 1983.

17 Pomerance A, Davies MJ. The pathology of the heart. London: Blackwell Scientific Publications, 1975.

18 Longauer F, Takac M, Halásová K. Über Schädigung des Reizleitungssystems bei Wegenerscher Granulomatose. Zeitschrift für Kreislaufforschung 1969; 58: 412-21. 